\title{
The importance of conflict characteristics for the diffusion of international mediation
}

\author{
Tobias Böhmelt \\ University of Essex, United Kingdom, and ETH Zurich, Switzerland ${ }^{1}$
}

\begin{abstract}
This article argues that similar conflict characteristics form links between crises, which signal the relevant actors, i.e., the belligerents and the potential mediator(s), that a comparable approach in terms of third-party mediation could be suitable across these disputes - even if the relevant parties are not the same. That is, demand (antagonists) and supply-side actors (mediators) are likely to employ the heuristic of learning from and emulating the mediation behavior in similar crises. The empirical analysis, employing data from the International Crisis Behavior project, shows that comparable patterns in violence, arguably the most visible and salient conflict characteristic, are associated with mediation traveling across crises; other dispute characteristics incorporated into spatial lags are not, however. Hence, particularly as domestic/unit-level (monadic) influences are controlled for, the effect of common exposure is taken into account, and different estimation strategies are used, the results emphasize that there is a genuine diffusion process via common levels of violence in the context of international mediation.
\end{abstract}

\section{Keywords}

crisis characteristics, diffusion, international mediation, spatial dependency

\section{Acknowledgements}

I thank Jennifer Larson, Michael Ward, Oliver Westerwinter, Amanda Murdie, Zeev Maoz, Erik Gartzke, Stephen Gent, Kyle Beardsley, Molly Melin, and especially Håvard Mokleiv Nygård as well as four anonymous for helpful comments.

TOBIAS BÖHMELT, b. 1982, PhD in International Relations (University of Essex, 2010); Reader (Associate Professor) in the Department of Government at the University of Essex (2013- ); Research Fellow at ETH Zurich (2010- ); main research and teaching interests: quantitative analysis of conflict and cooperation, environmental politics, international mediation, military effectiveness, and network analysis.

\footnotetext{
${ }^{1}$ Corresponding author: tbohmelt@essex.ac.uk
} 


\section{Introduction}

If a crisis's belligerents cannot find a peaceful solution themselves, international mediation is a frequently used tool. ${ }^{2}$ Mediation is driven by both demand and supply (Beardsley \& Greig, 2009), and the existing literature identifies several associated factors that influence a conflict's chances to see mediation (e.g., Greig, 2005; Greig \& Regan, 2008; Wallensteen \& Svensson, 2014). However, this work largely focused on 'domestic' or 'unit/crisis-specific' determinants, i.e., monadic factors such as the belligerents' level of democracy. Arguments for 'trans-unit' influences, i.e., mechanisms suggesting that characteristics of one conflict influence the chances of mediation in another, have largely been neglected. Do such transunit influences exist?

The policy diffusion literature emphasizes that actors in one national context may be influenced by actors in other states (e.g., Elkins \& Simmons, 2005; Gilardi, 2012). I correspondingly argue that, in their search for an effective strategy to end a conflict, conflict parties (demand side) and/or the potential mediator (supply side) learn from and emulate other, similar crises. Focusing on similarity as a link between two crises $i$ and $j$ is a useful heuristic, helping the actors on both the demand and supply side to make difficult decisions under uncertainty. Thus, transnational links to other crises - in the form of the similarity of conflict characteristics - help to explain the likelihood of mediation in crises 'at home.'

There is, in fact, anecdotal evidence for mediation diffusion: according to Sørbø et al. (2011), Norway's previous mediation interventions in the Middle East, creating the image of a 'global peace broker,' made Sri Lankan President Chandrika Kumaratunga requesting mediation from Norway in her country as well. Evidently, this is only a selected illustration

\footnotetext{
${ }^{2}$ The data I employ focus on crises, which are defined according to three criteria (Brecher \& Wilkenfeld, 2010: 12): there must be a threat to a state's basic values, there is a heightened risk of military action, and there is only a finite time horizon in which a state can respond. I use the terms 'crisis,' 'dispute,' and 'conflict' interchangeably. Finally, Bercovitch, Anagnoson \& Wille (1991: 8) define mediation as 'a process of conflict management where disputants seek the assistance of, or accept an offer of help from, an individual, group, state, or organization to settle their conflict or resolve their differences without resorting to physical force or invoking the authority of the law.'
} 
and limited to the same mediator across different crises. But is there systematic evidence that mediation diffuses from one crisis to another - even if the relevant actors (belligerents and the (potential) mediator) are not the same?

While earlier work (Böhmelt, 2015) focuses on the geographical proximity between crises and finds that mediation travels across conflicts if they occurred in the same region, it remains unclear which specific channels are responsible for this diffusion. That is, geographic proximity is not conditioned on some factor, but merely interpreted as capturing common security dynamics, regional security issues, or norms of conflict resolution. Put differently, geographically contiguous crises are disproportionately influenced by the same dynamics (Kathman, 2010; 2011). This mirrors Crescenzi et al. (2011) who demonstrate that distance is associated with the occurrence of conflict management. Hence, the geographic clustering of international mediation strongly suggests that its likelihood in one conflict is not only determined by factors of that individual conflict (i.e., unit-specific effects pertaining to the crisis in question), but that other, neighboring crises also influence the likelihood of whether we see mediation or not, i.e., there are trans-crisis influences (see also Buhaug \& Gleditsch, 2008). However, 'space is more than geography' (Beck, Gleditsch \& Beardsley, 2006) and the actual mechanisms at work for the within-region diffusion of mediation are less well understood (Buhaug \& Gleditsch, 2008).

In order to shed light on this, I focus on conflict characteristics - one of the most critical dimensions of crises (Bercovitch \& Langley, 1993; Bercovitch \& Houston, 2000; Kathman, $2010 ; 2011)$ - and argue that a 'common nature of the dispute' constitutes a link between crises that, in turn, motivates the diffusion of mediation. Building on the claim that mediation is driven by demand and supply (Beardsley \& Greig, 2009), I contend that the all actors involved are likely to employ the heuristic of learning from and emulating structurally similar conflicts. Leaders constantly face difficult decisions under uncertainty and, hence, 
they tend to use 'cognitive shortcuts' by comparing their circumstances and policies with others (Kahneman et al., 1982). These shortcuts are essentially heuristics - guidelines for action that should lead to reasonable results (Kahneman \& Tversky, 1979; Gale \& Kariv, 2003). I suggest that one such a heuristic could be based on the similarity of characteristics across crises. We know, for instance, that particularly the more difficult, i.e., more violent and salient disputes attract mediation (Gartner \& Bercovitch, 2006). While this is a domestic or unit-level factor, common levels of violence or issue salience constitute a trans-crisis informational tie between conflicts that may be linked to a learning and emulation process of the relevant actors. That is, if two conflicts have, e.g., a similar level of violence (even at equally low levels) and one has seen mediation before, actors in the other conflict might observe, learn from, and emulate this. The outcome is in turn that they believe that a comparable approach of third-party mediation could be suitable in that second crisis as well. Ultimately, this article advances the argument that mediation diffuses due learning from and emulating those conflicts, which are linked via the ties of common conflict characteristics even if the relevant actors are not the same across crises.

The findings are robust across different model specifications, estimation techniques, and while controlling for a number of 'exogenous-external conditions or common shocks and spatially correlated unit level factors' (Franzese \& Hays, 2007: 142), which ensure to rule out the possibility that what appears to be mediation diffusion across crises is the result of common exposure or clustering. I contribute to the study of networked international politics as, on one hand, my theoretical argument is based on the rationale that specific units (crises) do not exist in isolation from each other, but - depending on some degree of connectedness (links) - may very much be interdependent. This addresses a core concept of network analysis: 'complex interdependence' (see Hoff \& Ward, 2004; Dorff \& Ward, 2013). On the other hand, I elaborate on the relationship between spatial econometrics and network analysis 
with my focus on the broader diffusion literature: while there is anecdotal evidence that mediation travels from one crisis to another, my study is the first to provide systematic evidence relying on spatial econometrics empirically and, theoretically, arguments based on network analysis and diffusion. In fact, like network analysis, spatial econometrics allows me to 'account for extra-dyadic relations' among crises (Dorussen, Gartzke \& Westerwinter, 2016). The implication of my work is that an important mechanism for conflict resolution 'at home' is emulation and learning by the relevant actors with a view to address their dispute more effectively. The conclusion that conflict actors respond to other conflicts introduces another very important external factor for our understanding of how mediation evolves; namely, crises, and all actors therein, are influenced by other crises' conflict characteristics and mediation. This finding also contributes to the vast literature on mediation that has largely focused on purely 'domestic' or unit-level influences so far.

Second, while earlier work (Böhmelt, 2015) demonstrates that mediation diffuses, the underlying mechanism for this has not been identified. This article offers a more nuanced perspective, allowing us both theoretically and empirically to unpack this 'black box' and to shed more light on which ties between conflicts actually motivate the supply and demand sides to learn and emulate. Eventually, when controlling for domestic-level influences and the effect of common exposure, I can demonstrate that common conflict characteristics matter even across different estimation strategies, but it is only a mutual level of violence that drives the findings. I do not find evidence for other joint characteristics such as ethnic conflicts, salience, or protracted disputes and, hence, they are unrelated to mediation diffusion.

Third, I also consider the likelihood that actors are more willing and likely to learn from previous successes, i.e., effective mediation attempts in other conflicts. While I discuss a series of arguments for and against this claim, the results show that outcomes of previous mediations in other conflicts hardly influence the learning and emulation of the actors in 
another conflict. Put differently, mediation does diffuse via the channel of common levels of violence, but this largely occurs independently from the rate of success in other interventions.

\section{Literature: The diffusion of mediation within and across disputes}

The determinants of mediation in both interstate and civil conflicts have been widely studied. ${ }^{3}$ One core finding states that prior mediation in a particular dispute motivates further mediations. The belligerents (demand side) and the (potential) mediator (supply side) learn that mediation, even if it was ineffective before in resolving the dispute completely, could help addressing the underlying issues of contention. Hence, these actors rely on mediation again (e.g., Regan and Stam, 2000). For instance, Bercovitch \& Houston (2000: 183) highlight that 'the feedback from previous events includes information, experience, learning, and understanding gained by the mediator and the parties.' Melin (2011: 698) emphasizes that mediation attempts 'are not independent, with subsequent efforts at least commencing with more information than was available at the previous one' (see also Greig \& Regan, 2008: 765).

The mechanisms leading to this 'diffusion of mediation' over the course of one dispute are primarily related to what the general diffusion literature coined 'learning' and 'emulation' (e.g., Dolowitz \& Marsh, 2000; Elkins \& Simmons, 2005; Gilardi, 2012). Specifically, mediation and the outcome of the process are characterized by uncertainty (e.g., Beardsley, 2008; 2011). Parties might then rely on their own experience (belligerents) or the experience of others (e.g., other, previous mediators) to 'estimate the likely consequences of policy [mediation],' i.e., learning (Gilardi, 2012: 463). Alternatively, according to emulation, in situations of uncertainty, actors simply pursue those policies that have been implemented

\footnotetext{
${ }^{3}$ See Wallensteen \& Svensson (2014) for an excellent literature review.
} 
before by themselves or others due to their (policies') 'normative and socially constructed properties' (Gilardi, 2012: 466f). ${ }^{4}$

However, while the general literature suggests that policies - or, as in this case, mediation - can diffuse across units (crises), most of the existing mediation literature only focuses on different mediation attempts over the course of one dispute. I previously sought to extend this perspective by arguing that learning and emulation occur, and, ultimately, mediation diffuses across different crises that may not even have the same mediators or belligerents (Böhmelt, 2015). According to spatial contagion effects, mediation in one conflict is not only determined by factors of an individual crisis, but regional influences. These regional influences are empirically captured by geographical proximity and I suspected that this joint regional membership pertains to a similar security culture, regional dynamics, and norms.

There is thus evidence that mediation diffuses within and across crises, but our knowledge about the latter remains limited. Theoretically, it is merely assumed that geographical proximity captures common cultural norms, regional security dynamics, and norms. This assumption could be too strong, though. For example, both the UK and Greece belong to the same geographical region of Europe, but their respective crises, e.g., the Cod Wars between the UK and Iceland on one hand and, on the other hand, the various crises between Greece and Turkey, may have very few 'dynamics' or 'norms' in common. Empirically, only focusing on geographical proximity neither allows us to identify the actual channel of diffusion nor does it provide much control for what Buhaug \& Gleditsch (2008: 216) call the 'reverse Galton's problem:' earlier findings of mediation diffusion 'could be simply due to a corresponding distribution of relevant state [domestic or unit/crisis-specific] characteristics' (Buhaug \& Gleditsch, 2008: 216) that are correlated with mediation. This, nonetheless, is hardly related to a deliberate and genuine process of mediation diffusion. As Buhaug \&

\footnotetext{
${ }^{4}$ It is generally difficult to distinguish between these mechanisms in quantitative studies (Ward \& Cao, 2012: 1096).
} 
Gleditsch (2008: 216) conclude, 'we would face a reverse Galton's problem if we try to evaluate evidence for spatial contagion without first considering relevant unit attributes that may be both spatially clustered and potentially related' (emphasis added) to mediation onset.

I therefore seek to offer a more accurate and disaggregated perspective both theoretically and empirically. I first develop a theoretical argument for why we might observe mediation diffusion across regionally proximate crises that are linked to each other via similar conflict characteristics. While controlling for domestic-level influences, taking into account the effect of common exposure, and using different estimation strategies, I then empirically test the theoretical expectations by examining common conflict-characteristic linkages between crises in 1918-2007 and how they affect the likelihood of mediation.

\section{The diffusion of mediation via common conflict characteristics}

In one of the first steps toward identifying the specific channels of diffusion that might allow mediation travelling from one dispute to another, I focus on common conflict characteristics. The nature of a conflict, e.g., the level of violence, salience, or intensity, is one of the major determinants of mediation both from a supply and demand perspective (e.g., Beardsley \& Greig, 2009; Bercovitch \& Houston, 2000; Bercovitch \& Langley, 1993). The more difficult a conflict is (or becomes), the more likely that the belligerents realize that they are simply not able to solve a conflict on their own, but need help from outside (Regan \& Stam, 2000; Greig, 2005; Melin, 2015). From a supply side, the more intense, violent, or salient a specific crisis, the more likely it is that its negative externalities harm other nations not only in the same region, but globally (see also Buhaug \& Gleditsch, 2008; Kathman, 2010; 2011). This also increases the chances of mediation. However, while those arguments can predict why some belligerents ask for mediation or some mediators offer to intervene due to the characteristics of one specific crisis, it is less clear why or how these conflict features work as trans-crisis 
influences leading to the diffusion of mediation.

The belligerents and the potential mediator face uncertainty in the conflict process (e.g., Beardsley, 2008; 2011). It is thus difficult to assess whether mediation should be pursued, since it might be suitable in one situation, but less so in another (Melin, 2015). ${ }^{5}$ To cope with this uncertainty and to decide whether mediation is the 'right tool' in a specific context, I argue the demand and supply-side actors are likely to rely on 'cognitive shortcuts' by comparing their circumstances with other, similar ones (see Kahneman, Slovic \& Tversky, 1982; Tversky \& Kahneman, 1982): the antagonists and the potential mediator in a crisis employ the heuristic of learning from and emulating the mediation behavior in other, similar crises abroad. Consequently, similarity in conflict characteristics serves as an available precedent for the actors in another crisis.

Weyland (2005), in fact, claims that diffusion under uncertainty is guided by the use of cognitive heuristics, and emulating and learning from similar units may be 'one of the simplest and most effective cognitive heuristics in the calculation of utilities' (Elkins \& Simmons, 2005: 45). Kahneman and Frederick (2002: 53) define heuristics as 'judgment is modified by a heuristic when an individual assesses a specified target attribute of judgment by substituting another property of that object - the heuristic attribute - which comes more readily to mind.' I contend that the similarity of another crisis context could eventually 'come to mind,' particularly as they are observable. Therefore, conflict actors relying on whether a foreign, similar crisis had seen mediation to judge whether this could also be an option 'at home' employ a heuristic.

According to Tversky \& Kahneman (1982: 164), 'a person is said to employ the availability heuristic whenever he estimates frequency or probability by the ease with which instances or associations can be brought to mind.' That is, suppose the conflict actors try to

\footnotetext{
${ }^{5}$ In light of this, I assume that the actors involved have the 'sincere' motive to end a conflict. I examine this assumption thoroughly in the appendix.
} 
assess the probability with which mediation might be suitable for their context as well. If they use the availability heuristic, this probability will increase with the number of instances they can recall when other, similar crises before adopted mediation. To answer the broader question of how likely it is to belong to the set of 'similar conflicts,' conflict actors might then rely on the representativeness heuristic 'in which the probabilities are evaluated by the degree to which A resembles B' (Tversky \& Kahneman, 1974: 1124) - here, this is the extent to which the focal conflict resembles another dispute. Aspects that matter include visible or observable characteristics - and most conflict characteristics qualify for that.

In fact, the use of heuristics has long been a subsidiary theme in the literature. For example, Leng \& Regan (2003: 436) suggest that belligerents and the (potential) mediator use a similar culture as a heuristic for fewer coordination costs between them that should make both mediation and an effective outcome more likely (Bakaki, Böhmelt \& Bove, 2015). Simmons \& Elkins (2004: 176) similarly state that '[t]he policies of culturally similar countries are perceived to (and in fact may) contain highly relevant information on the appropriateness of a particular policy in a specific context of shared values.' Hence, if two conflicts share the same conflict characteristics, a heuristic, i.e., a link is given that facilitates the flow of information between the disputes - and, eventually learning or emulation by the relevant actors. Following Regan \& Stam (2000: 244), the heuristic of learning from and emulating the mediation behavior in similar conflicts 'increases the knowledge that the parties hold regarding their own and their adversaries' positions, potential compromises, and the costs of continued conflict.' A common set of conflict characteristics then signals to the actors of a 'new' conflict that mediation is a suitable tool for addressing the underlying grievances - if mediation has been used before. In other words, disputants and (potential) mediators are responsive to conflict characteristics, yet not only with regard to 'their own' conflict (see Greig, 2015), but also across different crises. 
It is likely, though, that primarily visible/observable characteristics qualify as learning and emulation heuristics, which induce the convergence to the same outcome, i.e., mediation if a previous crisis has experienced this. Conflict characteristics per se are a major and potentially very visible determinant of mediation (Beardsley \& Greig, 2009; Bercovitch \& Houston, 2000). Bercovitch \& Langley (1993: 675) emphasize accordingly that '[i]t seems a truism to suggest that the nature of a dispute will have a significant impact on the success or failure of a mediation attempt. [...] Similarly, Ott (1972) argues that "the success or failure of mediation is largely determined by the nature of the dispute, with the characteristics and tactics of the mediator marginal at best" (p. 597).' Subscribing to these claims that common conflict characteristics are visible, salient heuristics, learning and emulation make demand and supply-side actors perceive that if mediation has been employed before, it is also suitable to their context and could work in the 'new,' current crisis.

H1: Demand and supply for mediation in one crisis $i$ respond to the mediation behavior of a previous crisis $j$ if both crises are connected via the link of common conflict characteristics.

\section{The diffusion of effective mediation via common conflict characteristics}

Kahneman \& Frederick (2002) also emphasize that using heuristics can induce poor decisionmaking as relevant information is ignored. Thus, learning from and emulating other crises that are 'simply' similar in their characteristics could lead to misleading strategies. This argument suggests that conflict parties are likely to consider contextual, conditioning factors as well when using information on other, similar crises. A number of conditioning factors may apply, but I focus on the degree of effectiveness of previous mediation attempts in similar crises abroad.

Actors of one dispute perhaps only learn from and emulate previous, successful mediations 
in other similar disputes, and thus pursue mediation in their comparable context only when this success criterion is met. For instance, why should conflict actors perceive mediation as a potentially effective conflict-resolution tool if it failed to bring peace in other instances? However, the previous literature has not (yet) reached consensus on whether actors are more likely to learn from success or failure. By implication, it is unclear whether it is successful mediations that effectively end a conflict or unsuccessful ones where a mediation attempt is not able to induce peace, which influence the likelihood of mediation in the focal crisis. In fact, there are arguments that actors are likely to learn from both mediation success and failure (see, e.g., Bercovitch \& Houston, 2000; Greig, 2005; Greig \& Regan, 2008; Melin, 2011).

On one hand, some scholars (e.g., Bennett, 1991; Lee \& Strang, 2003; Gilardi, 2012: 466) contend it is primarily success that matters for learning and emulation processes. That is, only if mediation was effective in one crisis, the actors in another crisis will perceive this as crucial, which then works as a heuristic and forms a link that facilitates learning and emulation. On the other hand, recent research from the literature on cognitive heuristics also considers how 'positive or negative' experiences can influence learning and emulation (e.g., McDermott et al., 2008). In this literature, negative experiences, which mirror ineffective mediation in my context where the mediator is unable to bring peace to a conflict, could have a stronger cognitive effect than a positive experience, i.e., peace is created as mediation was successful (see Baumeister et al., 2001). For example, Khong (1992) focuses on leaders' decision making and their heuristics in light of other, similar actors' actions. It is found that it is basically negative factors that tend to have a stronger impact on learning and emulation, and, in turn, decision-making.

In light of these opposing arguments and findings, it follows that, in addition to the relevant informational challenge to process information of failed vs. successful mediation 
attempts (Kebschull, 1994), actors may not be able to disentangle the diffusion effects stemming from outcomes, but they elaborate their decisions in more general terms of mediation occurrence in other crises, i.e., what I claim in my first hypothesis (see also McDermott 1998). The following hypothesis on the possible direction of learning and emulation based on effective mediations then follows the first line of argumentation, although I note that the use of heuristics via learning and emulation may well work for previously failed mediations, too (see Khong, 1992), or is unrelated to the success criterion altogether (see Kebschull, 1994).

H2: Demand and supply for mediation in one crisis $i$ only respond to effective mediation of a previous crisis $j$ if both crises are connected via the link of common conflict characteristics.

\section{Research design}

Data and dependent variable

I rely on the cross-sectional data from the International Crisis Behavior (ICB) project (Brecher \& Wilkenfeld, 2010; see also Wilkenfeld et al., 2003) to empirically test my hypotheses. In the most recent $\left(10^{\text {th }}\right)$ release, these data consist of 455 crises between 1918 and 2007, while a crisis is defined according to the criteria in Footnote 1. I use the ICB's system-level data and, hence, the unit of analysis is an individual crisis. ${ }^{6}$

The dependent variable is mediation onset, which is operationalized via the ICB's MEDIATE item coding whether a crisis has seen at least one mediation attempt between its onset and termination (1) or not (0). For defining mediation, the ICB project follows

\footnotetext{
${ }^{6}$ Therefore, the sample also includes cases in which mediation did not occur. This, and the fact that the data are not limited to cases that become militarized at some point, circumvents the issue of selection bias to a great extent (Gartner \& Bercovitch, 2006).
} 
Bercovitch, Anagnoson \& Wille (1991: 8) as outlined in Footnote 1. According to the data, 141 (31 percent) of all 455 crises have seen at least one mediation attempt over their course. ${ }^{8}$

\section{Explanatory variables}

In order to capture spatial dependencies as my core explanatory variables, (Franzese \& Hays, 2007; Beck, Gleditsch \& Beardsley, 2006), I rely on several specifications of $\boldsymbol{W y}$, which stands for the product of a row-standardized connectivity matrix $(\boldsymbol{W})$ and the observed values of the dependent variable $(y) .{ }^{9}$ Due to the cross-sectional nature of my data, the connectivity matrix is defined as a $N x N$ matrix with an element $w_{i, j}$ capturing the relative connectivity of unit (crisis) $j$ to unit (crisis) $i$. The spatial lag then gives a weighted average of other observations, with each weight specified by $w_{i, j}$, while the spatial coefficient of $\boldsymbol{W} y, \rho$, captures the strength of interdependence.

Calculating a spatial lag for cross-section data via a symmetric $N x N$ matrix induces simultaneity, however, i.e., every unit $i$ is influenced by every unit $j$ and vice versa, which, in turn, means that the spatial lag is endogenous (Franzese \& Hays, 2007). Accordingly, in order to ensure that the spatial impact of a crisis is directional and not reversible, I consider only those crises as being potentially able to influence a specific dispute if they occurred before a conflict in question, i.e., the spatial lags' values do not give a weighted average of all other crises from 1918 to 2007, but only from those in previous years. This approach mirrors using an asymmetric, i.e., directed, connectivity matrix.

Following my theoretical rationale, I measure the links between two crises via their degree of similarity in dispute characteristics while all these links are additionally weighted by geographical proximity. The latter requirement induces that the values of the connectivity

\footnotetext{
${ }^{7}$ I outline the exact coding descriptions in the appendix.

${ }_{9}^{8}$ Due to missing values, the sample used for the analysis comprises 449 crises.

${ }^{9}$ I return to the issue of row standardization in the appendix.
} 
matrices for the four spatial lags introduced below automatically receive a value of 0 if two crises did not occur in the same region - independent from whether they have conflict characteristics in common or not. The data for geographical proximity are taken from the ICB's variable on the five regions of dispute origin: Africa, Americas, Asia, Europe, and the Middle East. ${ }^{10}$ This approach ensures that my results are comparable to Böhmelt (2015), but also extends the latter as I consider conflict characteristics, i.e., we are able to identify the underlying mechanism for the actual association between crises' geographical proximity and mediation diffusion. As a result, with this weighting procedure, we can identify the genuine diffusion channels from an intra-regional perspective (for the same approach, see also Buhaug \& Gleditsch, 2008). ${ }^{11}$

I focus on four key conflict characteristics, which leads to four different spatial lags pertaining to $H 1$ : ethnicity, protracted conflicts, geostrategic salience, and violence. First, ethnopolitical and identity-based disputes are more difficult to settle and agreements are less likely to be stable in a fractionalized environment with competing ethnic groups (e.g., Kaufmann, 1996). The ICB data provide the dichotomous ETHNIC item (Brecher \& Wilkenfeld, 2010: 57), which I used to construct a spatial lag based on a connectivity matrix in which each element $w_{i, j}$ measures whether dispute $i$ and dispute $j$ occurred in the same region and have an ethnic component in common (1) or not (0). As a result, non-ethnic conflicts, independent of whether they occurred in the same region (and independent of whether the first crisis was mediated), receive zeros in the weighted matrix. Since I require asymmetric matrices (explained above), I also replaced all $w_{i, j}$ values of 1 with 0 if a potential source crisis $j$ broke out after or in the same year as the target crisis $i$.

\footnotetext{
${ }^{10}$ The ICB data do not contain precise information on the country or exact geographical location a dispute took place in (Brecher \& Wilkenfeld, 2010: 53). Therefore, taking, e.g., land-based contiguity of disputes or between the belligerents is prevented by the lack of coding.

${ }^{11}$ This approach is also based on Kathman's (2011) argument that instabilities are more common in specific regions, which may then affect the use of heuristics.
} 
Second, protracted conflicts are 'situations of extended duration, fluctuating interactions, spillovers of hostility into all aspects of relations, strong forces tending to restore equilibrium, and characterized by indefinite continuation' (Brecher \& Wilkenfeld, 2010: 55). For example, there was a protracted conflict in the former Yugoslavia between 1991 and 1999 according to the ICB. This conflict comprised three individual crises: Yugoslavia I (Croatia-Slovenia 1991; ICB ID 397), Yugoslavia II (Bosnia 1992; ICB ID 403), and Kosovo (1999; ICB ID 430). While all these crises are coded as separate cases in the data, they are in fact very much related to and not independent from each other: they belong to a protracted conflict. Thereby, the protracted conflict item also captures recurring conflicts, i.e., crises that are related to some earlier hostility between the same actors.

While it is thus not only crucial to capture these dependencies between crises from an empirical perspective (as, in fact, the belligerents do hardly vary across these crises and, hence, mediation might diffuse more easily), Gartner \& Bercovitch (2006) or Bercovitch, Anagnoson \& Wille (1991) theoretically contend that protracted disputes are also more likely to see mediation. These tough cases pose a more severe threat to the belligerents and the international environment - including prospective mediators. This argument can be extended to the level of violence. ${ }^{12}$ The more violent a dispute, the higher the likelihood that the belligerents' attitudes are hardened and the conflict cycle has escalated (Bercovitch \& Langley, 1993: 676).

Against this background, I consider two additional spatial lags. On one hand, I constructed a spatial lag based on a connectivity matrix in which each element $w_{i, j}$ measures whether dispute $i$ and dispute $j$ occurred in the same region and belong to an underlying protracted conflict (1) or not (0). Consequently, non-protracted conflicts, independent of whether they occurred in the same region or not (and independent of whether the first crisis was mediated)

\footnotetext{
${ }^{12}$ Given that these two spatial-lag variables are meant to capture similar influences, it may be the case that they are highly correlated with each other. However, m-STAR models (Hays, Kachi \& Franzese, 2010), which control for this possibility (Table I), do not question the substance of the other models.
} 
receive $0 \mathrm{~s}$ in the weighted matrix for this spatial lag. Again, I replaced all $w_{i, j}$ values of 1 with 0 if a potential source crisis broke $j$ out after or in the same year as the target crisis $i$. On the other hand, the ICB contains the variable VIOL capturing the intensity of a crisis on an ordinal scale: (1) no violence, (2) minor clashes, (3) serious clashes, and (4) full-scale wars. In order to operationalize a link between dispute $i$ and dispute $j$, I calculated the absolute difference $^{13}$ in violence-level distances between $i$ and $j$ and rescaled this so that higher values signify lower distances (i.e., a higher degree of similarity in the level of violence) for the values of $w_{i, j}$. If a potential source crisis $j$ broke out after or in the same year as the target crisis $i$, and in the absence of a common regional tie between these crises, $w_{i, j}$ takes the value of 0 (i.e., no link between two crises in the connectivity matrix).

While conflict characteristics are particularly visible determinants of mediation, given the literature's emphasis on third parties' preferences for ceasing the hostilities (Balch-Lindsay \& Enterline, 2000; Regan, 2002; Kathman, 2011), I expect particularly crises' links via the level of violence to be important. Thus, the level of violence may be the most visible, salient, and evident issue when it comes to mediation both from a supply and demand perspective. With regard to the supply side, Kathman (2011: 852) states that 'foremost, third parties may attempt to cease the hostilities. A number of studies argue this to be the primary goal of intervention, noting that while third parties may have a variety of political goals in intervention, none can be achieved without first ending the violence.' In terms of the demand side, Balch-Lindsay \& Enterline (2000: 623) observe that the costs pertaining to the violence of a crisis 'on the participants have a strong influence on the dynamics' of conflict.

\footnotetext{
${ }^{13}$ Calculating the absolute difference for the ICB's VIOL and GEOSTR (fourth spatial lag) items assumes that the differences between specific values of these variables have the same meaning. This is not necessarily true for ordinally scaled variables such as VIOL and GEOSTR, however. I thus calculated alternative links between crises for VIOL and GEOSTR that are based on Gower's similarity measure: $S_{i j k}=1-\frac{\left|x_{i k}-x_{j k}\right|}{\tau_{k}}$. Here, $x_{i k}$ pertains to the value of variable $k$ for observation $i, x_{j k}$ stands for the value of variable $k$ for observation $j$, and $\tau_{k}$ is the range of variable $k$. However, the results presented below are absolutely identical to those using Gower's measure.
} 
Finally, the GEOSTR variable from the ICB data refers to the salience of an international crisis as measured by the number of international systems the dispute affects (Brecher \& Wilkenfeld, 2010: 47). Originally, this variable takes the values of 1 (only one subsystem is affected) to 5 (the global system is affected by a crisis). Similar to the spatial lag based on violence, I take the absolute difference in levels of geostrategic salience between $i$ and $j$, and rescaled this variable so that higher values signify lower dissimilarities in salience for the values of $w_{i, j}$. Again, if a potential source crisis $j$ broke out after or in the same year as the target crisis $i$, and in the absence of a common regional tie between these crises, $w_{i, j}$ takes the value of 0 (i.e., no link between two crises in the connectivity matrix).

In light of the discussion on effectiveness leading to my second hypothesis, I also constructed a second set of spatial lags for $H 2$ that are based on the connectivity matrices described above, but are not multiplied with $y$ (i.e., my dependent variable, mediation onset). Instead, the underlying connectivity matrices are multiplied with a new variable, which captures only previous successful mediation attempts as coded by the ICB data's item MEDEFCT (Brecher \& Wilkenfeld, 2010: 67).

Since all spatial lags represent a weighted average of all other observations (excluding a respective dispute under study), with each weight specified in spatial terms, while the spatial coefficient $\rho$ captures the strength of interdependence, I expect a positive spatial coefficient $\rho$ for all these variables as higher values pertain to stronger interlinkages according to joint conflict characteristics between regional disputes. A positive and statistically significant spatial coefficient $\rho$ would constitute evidence for mediation diffusion.

\section{Control variables}

Mediation is unlikely to be exclusively driven by trans-crises interdependencies. Moreover, when examining a spatial contagion effect, we also have to account for other factors, 
particularly unit/crisis-specific or monadic factors that may be 'both spatially clustered and potentially related to conflict' (Buhaug \& Gleditsch, 2008: 216). Put differently, the spatial clustering of mediation we might observe could simply be driven by a corresponding distribution of relevant conflict (domestic) characteristics associated with that conflict. This 'reverse Galton's problem' (Buhaug \& Gleditsch, 2008: 12) has to be addressed by considering relevant unit attributes that are both spatially clustered and potentially related to the outcome. I control for such relevant alternative influences, i.e. 'exogenous-external conditions or common shocks and spatially correlated unit level factors' (Franzese \& Hays, 2007: 142), which are located at the 'domestic' level of conflicts (see Wallensteen \& Svensson, 2014). These control variables pertain to the demand and supply side of mediation, e.g., the unit-level level of violence may not only influence the antagonists' demand for mediation, but also affect a potential mediator's cost-benefit analysis of intervention. Considering these controls ensures that mediation contagion 'cannot be dismissed as a mere product of a clustering in similar [dispute] characteristics' (Buhaug \& Gleditsch, 2008: 230).

First, coming to the characteristics of the disputants, democracies might share the norm of peaceful conflict resolution. This should make democratic belligerents more likely to agree to mediation (e.g., Raymond, 1994). ${ }^{14}$ By using the dichotomous democracy measure from the ICB, I constructed a joint-democracy specification, i.e., this variable only receives the value of 1 if all disputants involved in a specific crisis are democracies ( 0 otherwise).

Second, antagonists that approximate military parity, i.e., neither side has a clear military advantage, are generally more likely to agree on mediation (Mason \& Fett, 1996: 550; Greig, 2005: 258). I employ the ICB's POWDISSY variable (Brecher \& Wilkenfeld, 2010: 57), which refers to the capability gap between adversaries in an international crisis. The extent of power or capability discrepancy in a crisis ranges from none, when all adversaries are at the

\footnotetext{
${ }^{14}$ For counterarguments, however, see, e.g., Ellis, Mitchell \& Prins (2010).
} 
same level of capability, to maximal discrepancy, e.g., when the main adversaries are a superpower and a small power. I take the natural logarithm to account for its skewed distribution and I expect this item to be negatively related to mediation onset.

Third, there is Duration, i.e., a variable that measures the time elapsed from the start of a crisis until its end. Including a duration item also corrects for possible temporal dependencies and selection effects (see Regan \& Stam, 2000). I introduce a log-transformed version of this variable. Fourth, following Franzese \& Hays (2007: 142) who suggest incorporating 'spatially correlated unit-level factors,' the conflict characteristics I used for the construction of the spatial lags are also introduced as domestic/unit-level (monadic) controls.

Finally, to further rule out the possibility of common exposure, i.e., spatial clustering that is not driven by crises' interdependence, I also include time-period dummies for the postWorld War I period (1919-1938), World War II (1939-1945), the Cold War (1946-1990), and the post-Cold War period (1991-2007). These dummies capture system-wide changes in technology or international institutions, and, more generally, 'exogenous-external conditions or shocks' that are common for all crises in a given period (Franzese \& Hays, 2007: 142; 2008). ${ }^{15}$

Against this background, obtaining significant estimates for the one of the spatial lags' coefficients while including all these controls substantially increases the confidence in the existence of a true mediation diffusion effect between crises.

\section{Empirical findings}

Using probit regressions as the main models, Model 1 (Table I) presents the results of the basic model, i.e., the spatial lags that are based on mediation efforts in other conflicts, but not outcomes. Model 2 then introduces the 'effectiveness-based' spatial lags instead of the

\footnotetext{
${ }^{15}$ The appendix summarizes the descriptive statistics of the variables discussed in this section. As demonstrated there, all variables are characterized by a sufficient amount of variance across crises.
} 
regular ones. I report coefficients and robust standard errors that address potential problems with heteroskedasticity. I also present substantive quantities of interest for the spatial lags in the form of simulated first differences. Here, I define a first difference as the change in the probability that Mediation $=1$ induced by an increase from the $25^{\text {th }}$ to the $75^{\text {th }}$ percentile of a variable in question while holding all other covariates at their median. Finally, I also present results for multiparametric spatiotemporal autoregressive (m-STAR) models (Hays, Kachi \& Franzese, 2010) in Models 3 and 4. The m-STAR model explicitly allows for a simultaneous inclusion of all spatial lags, while controlling for the case where connectivity, i.e., the selection into a network, might be endogenous to the dependent variable. ${ }^{16}$

Starting with interpreting the spatial lags, three of the four exert an insignificant impact on mediation onset. Moreover, the impact direction of $\boldsymbol{W}^{\text {Ethnic }}$ and $\boldsymbol{W}^{\text {Salience }}$ is actually negative. These findings are mirrored by the first differences presented in Figure 1. These results hardly support my expectations - mediation does apparently not diffuse through channels of common conflict characteristics. However, $\boldsymbol{W}^{\text {Violence }}$ exerts a positive effect that is statistically significant at the 5 percent level (Model 1). In substantive terms, Figure 1 shows that when moving from the $25^{\text {th }}$ to the $75^{\text {th }}$ percentile of $\boldsymbol{W}^{\text {Violence }}$, the predicted probability of a crisis to see mediation increases by about 15 percentage points. The m-STAR regression (Model 3) supports this finding: mediation diffuses between conflicts that are (a) located in the same region and (b) similar in terms of the level of violence. Hence, at least in terms of $\boldsymbol{W}^{\text {Violence }}$, I do obtain empirical support for a genuine mediation diffusion effect.

Interestingly, Models 2 and 4 offer little support for the claim that the actors are more likely to learn from and emulate previous effective mediations. All spatial lags are statistically insignificant and even $\boldsymbol{W}^{\text {Violence }}$ does no longer reach conventional levels of significance. This finding is robust across the different estimation strategies in Models 2 and 4, while adding or

\footnotetext{
${ }^{16}$ The m-STAR model is a linear model. Hence, Models 3 and 4 basically depict the results of a linear probability model, which suffers from built-in heteroskedasticity. However, as the substantive results do not differ across estimation strategies, the concerns over a bias due to this are lowered.
} 
dropping any of the controls does not affect this either. In other words, particularly in light of the results in Models 1 and 3, the supply and demand actors in a crisis do learn from and emulate all types of previous mediations. The outcome as such of these previous third-party interventions in other conflicts does not matter much, though.

Table I. The diffusion of international mediation via conflict characteristics

\begin{tabular}{|c|c|c|c|c|}
\hline & $\begin{array}{c}\text { (1) } \\
\text { S-probit: } \\
\text { Basic spatial } \\
\text { lags }\end{array}$ & $\begin{array}{c}\text { (2) } \\
\text { S-probit: } \\
\text { Effectiveness }\end{array}$ & $\begin{array}{c}\text { (3) } \\
\text { m-STAR: } \\
\text { Basic spatial } \\
\text { lags }\end{array}$ & $\begin{array}{c}\text { (4) } \\
\text { m-STAR: } \\
\text { Effectiveness }\end{array}$ \\
\hline $\boldsymbol{W}^{\text {Ethnic }}$ & $\begin{array}{l}-0.627 \\
(0.467)\end{array}$ & $\begin{array}{l}-0.262 \\
(0.491)\end{array}$ & $\begin{array}{l}-0.164 \\
(0.150)\end{array}$ & $\begin{array}{l}-0.034 \\
(0.161)\end{array}$ \\
\hline $\boldsymbol{W}^{\text {Protracted }}$ & $\begin{array}{c}0.519 \\
(0.683)\end{array}$ & $\begin{array}{c}0.224 \\
(0.776)\end{array}$ & $\begin{array}{c}0.161 \\
(0.201)\end{array}$ & $\begin{array}{c}0.047 \\
(0.236)\end{array}$ \\
\hline $\boldsymbol{W}^{\text {Violence }}$ & $\begin{array}{l}4.257 \\
(2.123)^{*}\end{array}$ & $\begin{array}{c}2.440 \\
(2.484)\end{array}$ & $\begin{array}{l}1.520 \\
(0.596)^{*}\end{array}$ & $\begin{array}{c}1.133 \\
(0.708)\end{array}$ \\
\hline $\boldsymbol{W}^{\text {Salience }}$ & $\begin{array}{l}-3.012 \\
(2.184)\end{array}$ & $\begin{array}{l}-0.734 \\
(2.584)\end{array}$ & $\begin{array}{l}-1.217 \\
(0.609)^{*}\end{array}$ & $\begin{array}{l}-0.613 \\
(0.730)\end{array}$ \\
\hline Democracy & $\begin{array}{l}0.295 \\
(0.178) \dagger\end{array}$ & $\begin{array}{c}0.246 \\
(0.183)\end{array}$ & $\begin{array}{l}0.089 \\
(0.053) \dagger\end{array}$ & $\begin{array}{c}0.076 \\
(0.053)\end{array}$ \\
\hline Power asymmetry $(\ln )$ & $\begin{array}{c}-0.075 \\
(0.063)\end{array}$ & $\begin{array}{c}-0.071 \\
(0.063)\end{array}$ & $\begin{array}{c}-0.025 \\
(0.018)\end{array}$ & $\begin{array}{c}-0.023 \\
(0.018)\end{array}$ \\
\hline Protracted conflict & $\begin{array}{c}-0.037 \\
(0.158)\end{array}$ & $\begin{array}{c}0.011 \\
(0.141)\end{array}$ & $\begin{array}{l}-0.011 \\
(0.046)\end{array}$ & $\begin{array}{c}0.007 \\
(0.042)\end{array}$ \\
\hline Geostrategic salience & $\begin{array}{l}-0.244 \\
(0.089)^{* *}\end{array}$ & $\begin{array}{l}-0.220 \\
(0.089)^{*}\end{array}$ & $\begin{array}{l}-0.069 \\
(0.022)^{* *}\end{array}$ & $\begin{array}{l}-0.063 \\
(0.023)^{* *}\end{array}$ \\
\hline Ethnic crisis & $\begin{array}{l}0.553 \\
(0.238)^{*}\end{array}$ & $\begin{array}{l}0.439 \\
(0.202)^{*}\end{array}$ & $\begin{array}{l}0.165 \\
(0.074)^{*}\end{array}$ & $\begin{array}{l}0.133 \\
(0.062)^{*}\end{array}$ \\
\hline Duration (ln) & $\begin{array}{l}0.625 \\
(0.221)^{* *}\end{array}$ & $\begin{array}{l}0.627 \\
(0.225)^{* *}\end{array}$ & $\begin{array}{l}0.207 \\
(0.049)^{* *}\end{array}$ & $\begin{array}{l}0.208 \\
(0.049)^{* *}\end{array}$ \\
\hline Violence & $\begin{array}{l}0.246 \\
(0.076)^{* *}\end{array}$ & $\begin{array}{l}0.280 \\
(0.078)^{* *}\end{array}$ & $\begin{array}{l}0.068 \\
(0.021)^{* *}\end{array}$ & $\begin{array}{l}0.077 \\
(0.021)^{* *}\end{array}$ \\
\hline Period I & $\begin{array}{l}-0.587 \\
(0.289)^{*}\end{array}$ & $\begin{array}{l}-0.622 \\
(0.273)^{*}\end{array}$ & $\begin{array}{l}-0.200 \\
(0.085)^{*}\end{array}$ & $\begin{array}{l}-0.201 \\
(0.081)^{*}\end{array}$ \\
\hline Period II & $\begin{array}{l}-1.557 \\
(0.399)^{* *}\end{array}$ & $\begin{array}{l}-1.520 \\
(0.368)^{* *}\end{array}$ & $\begin{array}{l}-0.284 \\
(0.102)^{* *}\end{array}$ & $\begin{array}{l}-0.282 \\
(0.099)^{* *}\end{array}$ \\
\hline Period III & $\begin{array}{l}-0.449 \\
(0.217)^{*}\end{array}$ & $\begin{array}{l}-0.421 \\
(0.215)^{*}\end{array}$ & $\begin{array}{l}-0.146 \\
(0.065)^{*}\end{array}$ & $\begin{array}{l}-0.135 \\
(0.065)^{*}\end{array}$ \\
\hline Constant & $\begin{array}{l}-0.749 \\
(0.407) \dagger\end{array}$ & $\begin{array}{l}-0.925 \\
(0.401)^{*}\end{array}$ & $\begin{array}{l}0.292 \\
(0.122)^{*}\end{array}$ & $\begin{array}{l}0.214 \\
(0.116) \dagger\end{array}$ \\
\hline Observations & 449 & 449 & 449 & 449 \\
\hline Log pseudo likelihood & -229.961 & -229.691 & -244.190 & -243.434 \\
\hline Wald $\chi^{2}$ & $84.90 * * *$ & $91.83 * * *$ & $75.35 * * *$ & $78.42 * * *$ \\
\hline
\end{tabular}

$\dagger$ significant at 10 percent; * significant at 5 percent; ** significant at 1 percent (two-tailed). Standard errors in parentheses. Period IV (post-Cold War) constitutes baseline category for temporal dummies. 
The results for my core variables lead to the following conclusions that link my empirical results to the theoretical framework. First, mediation does diffuse from one crisis to another, but this is primarily done via the channel of similar levels of violence. Hence, my theoretical argument applies and there is support for $H 1$ - but only under certain conditions. A common ethnic component, geostrategic salience, or protracted conflicts matter less and there is hardly any evidence for a diffusion effect in terms of these items' spatial lags.

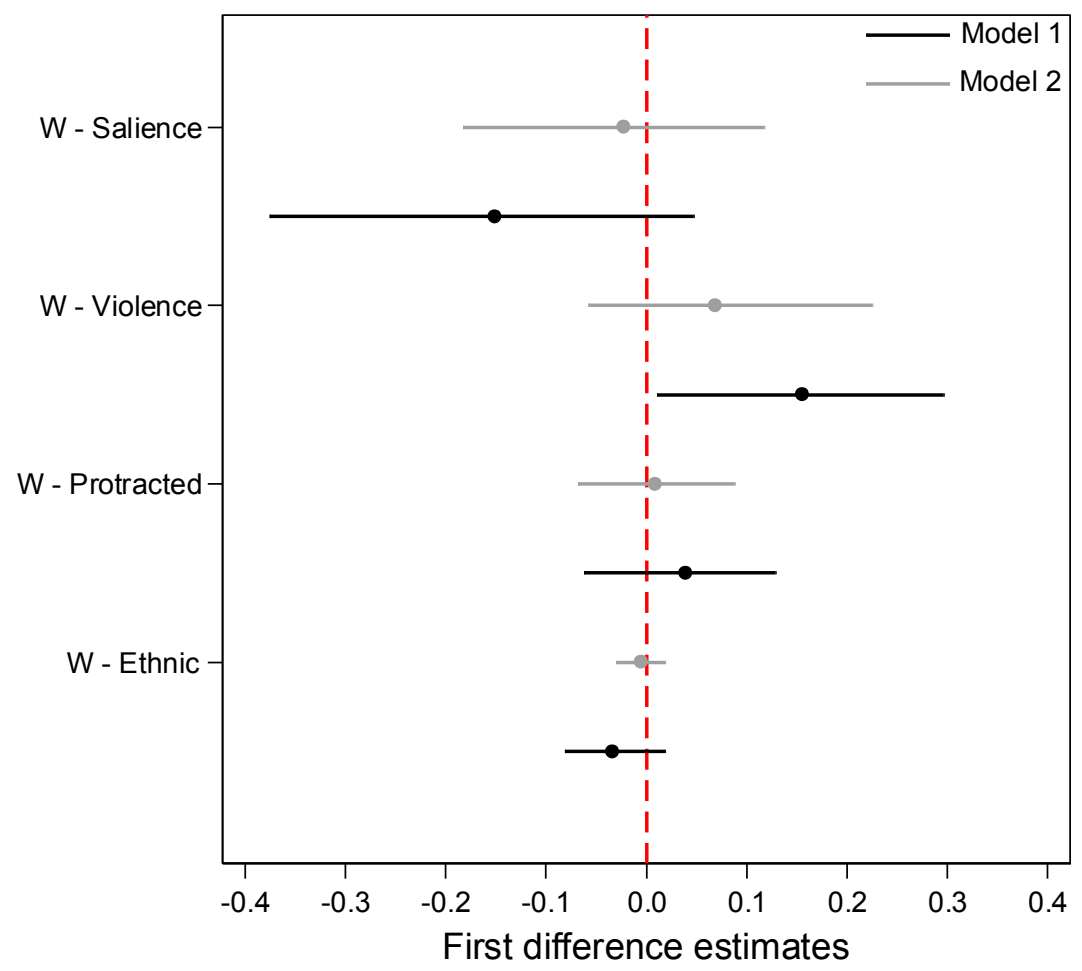

Figure 1. First differences

Graph based on Models 1-2. Horizontal bars pertain to 95 percent confidence intervals. First difference of 0 marked with vertical line. All variables except focal variable are held at their median value.

Second, what makes violence 'special' given the results suggesting that the heuristic of learning from and emulating the mediation behavior in other crises only works for a common level of violence? In general, conflict characteristics are a particularly salient and visible set of mediation determinants (Bercovitch \& Langley, 1993). However, according to Bercovitch 
\& Langley (1993) and various other sources cited above, it is particularly violence that matters. And, in fact, factors like the issue dimension (ethnic component, salience) or the complexity of a conflict (protracted crisis) all influence the level of violence of a conflict but it is unlikely that this applies the other way round (Bercovitch \& Langley, 1993: 687). Hence, violence is the most observable and salient factor of the set of conflict characteristics that, in turn, facilitates learning and emulation precisely because of its high visibility. Greig \& Regan (2008: 772) also highlight that violence levels pertain to the 'immediate, current costs of conflict experienced by the warring parties,' while other factors present more of 'a proxy of the longer-term costs of fighting.' This underlines the visibility of violence. And it may even be suggested (e.g., Bercovitch \& Houston, 2000) that violence is the only conflict characteristic so visible that allows the disputants to be aware that a moment is 'ripe' for resolution.

Third, in terms of my contributions, the main finding strongly goes beyond Böhmelt (2015) in that I am able to show which underlying mechanism leads to the diffusion of mediation from one regional crisis to another. In addition, my lack of support for $H 2$ suggests that those studies arguing that the heuristic via learning and emulation may also work for previously failed mediations (Khong, 1992) or is unrelated to the success criterion altogether (Kebschull, 1994) are likely to be more valid in the mediation context than those works claiming that it is only learning from success that matters. Hence, learning and emulation seem to be given for the heuristic of similar crises, while the outcome of their mediation attempts is unlikely to be of crucial importance.

Coming to the control covariates, most of them display results, which are in line with the previous literature (see Wallensteen \& Svensson, 2014). ${ }^{17}$ Also, despite the built-in

\footnotetext{
${ }^{17}$ Note, however, when including spatial lags, model coefficients (excluding the spatial coefficient $\rho$, though) provide information about the pre-dynamic impulses from the explanatory variables (Hays, Kachi \& Franzese, 2010: 409).
} 
heteroskedasticity of the linear m-STAR model, the results there are virtually identical to the probit regression models. Due to space limitations, I focus on the statistically significant results that are robust across models. First, although only the spatial lag based on violence is significant, my models strongly support the notion that longer, more violent, and ethnic crises are more likely to see mediation interventions. That is, while a diffusion effect is largely missing for these variables, these domestic, unit-specific characteristics still do attract mediation both from a supply and demand side. When raising Violence by one unit, the probability of mediation onset increases by about 7-8 percentage points according to the mSTAR models. In light of the finding for $\boldsymbol{W}^{\text {Violence }}$ discussed above, it should be noted that it is more likely that a higher level of violence only affects the likelihood of mediation onset positively at the 'domestic level,' but that higher intensity as such matters less at the

international level: according to $\boldsymbol{W}^{\text {Violence }}$, crises that are more similar in their levels of violence drive diffusion, and this may be unrelated to a high level of violence per se.

For Ethnic crisis, I obtain a slightly higher substantive effect of about 13-17 percentage points (when moving from 0 to 1 for this variable), while the marginal effect of Duration (ln) is at 0.21 . Hence, ethnic crises and those lasting for a long time may indeed be more difficult to settle, thus signaling that these are the hard cases, which are most in need for mediation (Gartner \& Bercovitch, 2006).

Finally, Geostrategic salience is negatively signed and significant in all models. In more intuitive ways, increasing Geostrategic salience by one unit decreases the probability of mediation by about 8.5 percentage points: the more salient a particular crisis is from a geostrategic perspective, the less likely it is that mediation onset occurs.

\section{Conclusion}

Mediation is driven by the demand of the belligerents and the supply of the third parties in a 
conflict (Beardsley \& Greig, 2009). The previous literature largely focused on 'unit-specific' characteristics, which neglected the importance of 'trans-unit' influences. If the latter have been considered, there was merely geographical proximity taken into account and it remained unclear whether a genuine diffusion mechanism was at work (Böhmelt, 2015).

I presented theoretical arguments and empirical evidence for why such a genuine 'neighborhood effect' (Buhaug \& Gleditsch, 2008) may indeed be present. I focused on common conflict characteristics as ties between crises and claimed that the actors' decisionmaking regarding supply and demand of mediation may be influenced by a learningemulation heuristic based on these shared characteristics. The empirical analysis demonstrated that mediation travels across crises that are similar in their level of violence. Similarities in other aspects such as salience and protracted or ethnic conflicts do not matter, however.

This research thus contributes in various ways to the literatures on mediation, policy diffusion, and networked international politics. Yet, several avenues for further research exist. First, if mediation diffuses across crises due to a similar violence level and, as I argued, the actors' employed learning-emulation heuristic, we might also observe that specific mediation techniques, e.g., facilitative, procedural, and directive/manipulation strategies, travel (see Melin, 2015). Similarly, the patterns I observed for mediation might apply for other forms of conflict management/resolution such as arbitration, adjudication, or peacekeeping; and it may well be that mediation travels via other channels linking crises, e.g., colonial history of countries or states' membership in intergovernmental organizations, other than similarities in regional crises' level of violence.

Second, my theory and the empirical strategy for testing it do not assume that the same mediator intervenes across conflicts. Belligerents and potential mediators observe what is happening in international affairs and based on their learning from and emulation of other 
conflicts, even if the actors there are different from the current context, might employ the same strategy. However, Melin (2015) or Böhmelt (2013) show that the effects we observe for mediation onset and effectiveness become stronger when taking the mediator's identify into account. That is, learning and emulation should be more present if the same mediator intervenes in different crises.

Finally, my work may also provide critical insights for policymakers' and practitioners' understanding of how conflict management works. Specifically, domestic or unit-specific factors matter for mediation, but international influences in the form of diffusion as well. In turn, my research has a clear policy implication: since learning from and emulating previous mediations in other crises increases the chances that mediation occurs in some other, similarly violent conflicts, then mediators may have an especially strong (and never before realized) impact on the futures of every other, similarly violent dispute.

In light of this, although my work demonstrates that the degree of effectiveness of previous crises hardly matters for the phenomenon of mediation onset $(H 2)$, it may well influence the prospects of success in the current crisis. Put differently, if mediation does indeed diffuse due to learning from and emulating other crises with similar violence patterns, it seems plausible that the strategies used in that earlier conflict to bring about a peaceful resolution will also work in the current dispute. Conversely, those techniques and strategies that did not work in an earlier, similar crisis are unlikely to work in the current context. From a scholarly point of view, we need to examine a different dependent variable, though, to fully address this: mediation effectiveness.

\section{Data replication}

The data set and do-files for the empirical analysis in this article can be found at http://www.prio.org/jpr/datasets. 


\section{References}

Bakaki, Zorzeta; Tobias Böhmelt \& Vincenzo Bove (2015) Barriers to coordination? Examining the impact of culture on international mediation occurrence and effectiveness. Political Studies, forthcoming.

Balch-Lindsay, Dylan \& Andrew Enterline (2000) Killing time: The world politics of civil war duration, 1820-1992. International Studies Quarterly 44(4): 615-642.

Baumeister, Roy; Ellen Bratslavsky, Catrin Finkenauer \& Kathleen Vohs (2001) Bad is stronger than good. Review of General Psychology 5(4): 323-70.

Beardsley, Kyle (2008) Agreement without peace? International mediation and time inconsistency problems. American Journal of Political Science 52(4): 723-740.

Beardsley, Kyle (2011) The mediation dilemma. Ithaca, NY: Cornell University Press.

Beardsley, Kyle \& Michael Greig (2009) Disaggregating the incentives of conflict management: An introduction. International Interactions 35(3): 243-248.

Beck, Nathaniel; Kristian Skrede Gleditsch \& Kyle Beardsley (2006) Space is more than geography: Using spatial econometrics in the study of political economy. International Studies Quarterly 50(1): 27-44.

Bennett, Colin (1991) What is policy convergence and what causes it? British Journal of Political Science 21(2): 215-233.

Bercovitch, Jacob; Theodore Anagnoson \& Donnette Wille (1991) Some conceptual issues and empirical trends in the study of successful mediation in international relations. Journal of Peace Research 28(1): 7-17.

Bercovitch, Jacob \& Allison Houston (2000) Why do they do it like this? An analysis of the factors influencing mediation behavior in international conflicts. Journal of Conflict Resolution 44(2): 170-202. 
Bercovitch, Jacob \& Jeffrey Langley (1993) The nature of the dispute and the effectiveness of international mediation. Journal of Conflict Resolution 37(4): 670-691.

Böhmelt, Tobias (2013) Failing to succeed? The cumulative impact of international mediation revisited. Conflict Management and Peace Science 30(3): 199-219.

Böhmelt, Tobias (2015) The spatial contagion of international mediation. Conflict Management and Peace Science 32(1): 108-127.

Brecher, Michael \& Jonathan Wilkenfeld (2010) Codebook for ICB1 - International crisis behavior project. System-level dataset - July 2010. ICPSR Study \#9286 - Version 10.0. Available at: http://www.cidcm.umd.edu/icb (Accessed on November 25, 2015).

Buhaug, Halvard \& Kristian Skrede Gleditsch (2008) Contagion or confusion? Why conflicts cluster in space. International Studies Quarterly 52(2): 215-233.

Crescenzi, Mark; Kelly Kadera, Sara McLaughlin Mitchell \& Clayton Thyne (2011) A supply side theory of mediation. International Studies Quarterly 55(4): 1069-1094.

Dolowitz, David \& David Marsh (2000) Learning from abroad: The role of policy transfer in contemporary policy-making. Governance 13(1): 5-24.

Dorff, Cassy \& Michael Ward (2013) Networks, dyads, and the social relations model. Political Science Research and Methods 1(2): 159-178.

Dorussen, Han; Erik Gartzke \& Oliver Westerwinter (2016) Networked international politics: An introduction. Journal of Peace Research: Forthcoming.

Elkins, Zachary \& Beth Simmons (2005) On waves, clusters, and diffusion: A conceptual framework. Annals of the American Academy of Political and Social Science 598(1): 3351.

Ellis, Glynn; Sara McLaughlin Mitchell \& Brandon Prins (2010) How democracies keep peace: Contextual factors that influence conflict management strategies. Foreign Policy Analysis 6(4): 373-398. 
Franzese, Robert \& Jude Hays (2007) Spatial econometric models of cross-sectional interdependence in political science panel and time-series-cross-section data. Political Analysis 15(2): 140-164.

Gale, Douglas \& Shachar Kariv (2003) Bayesian learning in social networks. New York: New York University Press.

Gartner, Scott \& Jacob Bercovitch (2006) Overcoming obstacles to peace: The contribution of mediation to short lived conflict settlements. International Studies Quarterly 50(4): 819-840.

Gilardi, Fabrizio (2012) Transnational diffusion: Norms, ideas, and policies. In: Walter Carlsnaes; Thomas Risse \& Beth Simmons (eds) Handbook of international relations. Thousand Oaks, CA: SAGE Publications, 453-477.

Greig, Michael (2005) Stepping into the fray: When do mediators mediate? American Journal of Political Science 49(2): 249-266.

Greig, Michael (2015) Nipping them in the bud: The onset of mediation in low-intensity civil conflicts. Journal of Conflict Resolution 59(2): 336-361.

Greig, Michael \& Patrick Regan (2008) When do they say yes? An analysis of the willingness to offer and accept mediation in civil wars. International Studies Quarterly 52(4): 759-781.

Hays, Jude; Aya Kachi \& Robert Franzese (2010) A spatial model incorporating dynamic, endogenous network interdependence: A political science application. Statistical Methodology 7(3): 406-428.

Hoff, Peter \& Michael Ward (2004) Modeling dependencies in international relations networks. Political Analysis 12(2): 160-175.

Kaufmann, Chaim (1996) Possible and impossible solutions to ethnic conflicts. International Security 20(4): 136-175. 
Kahneman Daniel \& Shane Frederick (2002) Representativeness revisited: Attribute substitution in intuitive judgment. In: Thomas Gilovich, Dale Griffin \& Daniel Kahneman (eds.) Heuristics and biases: The psychology of intuitive judgment. Cambridge: Cambridge University Press, 49-81.

Kahneman, Daniel; Paul Slovic \& Amos Tversky (eds) (1982) Judgment under uncertainty: Heuristics and biases. Cambridge: Cambridge University Press.

Kahneman, Daniel \& Amos Tversky (1979) Prospect theory: An analysis of decision under risk. Econometrica 47(2): 263-291.

Kathman, Jacob (2010) Civil war contagion and neighboring interventions. International Studies Quarterly 54(4): 989-1012.

Kathman, Jacob (2011) Civil war diffusion and regional motivations for intervention. Journal of Conflict Resolution 55(6): 847-876.

Kebschull, Harvey (1994) Operation 'Just Missed:' Lessons from failed coup attempts. Armed Forces \& Society 20(4): 565-79.

Khong, Yuen Foong (1992) Analogies at war: Korea, Munich, Dien Bien Phu, and the Vietnam decisions of 1965. Princeton, NJ: Princeton University Press.

Lee, Chang Kil \& David Strang (2003) The international diffusion of public sector downsizing: Network emulation and theory-driven learning. International Organization 60(4): 883-909.

Leng, Russell \& Patrick Regan (2003) Social and political cultural effects on the outcomes of mediation in militarized interstate disputes. International Studies Quarterly 47(3): 431452.

Mason, David \& Patrick Fett (1996) How civil wars end: A rational choice approach. Journal of Conflict Resolution 40(4): 546-568. 
McDermott, Rose (1998) Risk-taking in international politics: Prospect theory in American foreign policy. Ann Arbor, MI: University of Michigan Press.

McDermott, Rose; James Fowler \& Oleg Smirnov (2008) On the evolutionary origin of prospect theory preferences. Journal of Politics 70(2): 335-50.

Melin, Molly (2011) The impact of state relationships on if, when and how conflict management occurs. International Studies Quarterly 55(3): 691-715.

Melin, Molly (2015) Escalation in international conflict management: A foreign policy perspective. Conflict Management and Peace Science 32(1): 28-49.

Raymond, Gregory (1994) Democracies, disputes, and third-party intermediaries. Journal of Conflict Resolution 38(1): 24-42.

Regan, Patrick (2002) Third-party interventions and the duration of intrastate conflicts. Journal of Conflict Resolution 46(1): 55-73.

Regan, Patrick \& Allan Stam (2000) In the nick of time: Conflict management, mediation timing, and the duration of interstate disputes. International Studies Quarterly 44(2): 239260.

Simmons, Beth \& Zachary Elkins (2004) The globalization of liberalization. Policy diffusion in the international political economy. American Political Science Review 98(1): 171-189.

Sørbø, Gunnar; Jonathan Goodhand, Bart Klem, Ada Elisabeth Nissen \& Hilde Selbervik (2011) Pawns of peace: Evaluation of Norwegian peace efforts in Sri Lanka, 1997-2009. Oslo: Norwegian Agency for Development Cooperation.

Tversky, Amos \& Daniel Kahneman (1974) Judgment under uncertainty: Heuristics and biases. Science 185(4157): 1124-1131.

Tversky, Amos \& Daniel Kahneman (1982) Judgment under uncertainty: Heuristics and biases.” In: Daniel Kahneman, Paul Slovic \& Amos Tversky (eds.) Judgment under uncertainty: Heuristics and biases. Cambridge: Cambridge University Press, 3-22. 
Wallensteen, Peter \& Isak Svensson (2014) Talking peace: International mediation in armed conflicts. Journal of Peace Research 51(2): 315-327.

Ward, Hugh \& Xun Cao (2012) Domestic and international influences on green taxation. Comparative Political Studies 45(9): 1075-1103.

Weyland, Kurt (2005) The diffusion of innovations: How cognitive heuristics shaped Bolivia's pension reform. Comparative Politics 38(1): 21-42.

Wilkenfeld, Jonathan; Kathleen Young, Victor Asal \& David Quinn (2003) Mediating international crises: Cross-national and experimental perspectives. Journal of Conflict Resolution 47(3): 279-301. 